\title{
INTERDISCIPLINARY SURVEY TO INVESTIGATE ENERGY-RELATED OCCUPANT BEHAVIOR IN OFFICES - THE HUNGARIAN CASE
}

\author{
${ }^{1}$ Zsófia DEME BÉLAFI, ${ }^{2}$ András REITH \\ ${ }^{1}$ Department of Building Energetics and Services, Faculty of Architecture \\ Budapest University of Technology and Economics \\ Muegyetem rkp 3, Budapest, Hungary, e-mail: belafi@egt.bme.hu \\ ${ }^{2}$ Advanced Building and Urban Design, Kisfaludy u 38, Budapest, Hungary \\ e-mail: reith.andras@abud.hu
}

Received 31 December 2017; accepted 16 April 2018

\begin{abstract}
In recent years, both legislative instruments and market demand drive the construction industry towards high-performing, low-energy consuming buildings. However, without considering the human dimension, technologies alone do not necessarily guarantee high performance in buildings. Occupant behavior is a leading factor influencing energy use in buildings. To investigate and quantify the human dimension in a building's energy use, an international research study has been launched as part of project ANNEX66, organized by the International Energy Agency using an interdisciplinary framework. The framework is a synthesis of theories from building physics and social psychology including social cognitive theory, the theory of planned behavior, and the drivers-needs-actions-systems ontology for energy-related behaviors. As a research tool, an online survey was designed to collect cross-country responses from office occupants among 14 universities within 6 countries from 4 continents. This paper introduces results and findings of the Hungarian data collection campaign conducted among 207 occupants in 6 universities across the country.
\end{abstract}

Keywords: Occupant behavior, Energy consumption, Office buildings

\section{Introduction}

Energy-related occupant behavior in buildings is one of the six influencing factors of building performance [1], [2], including climate, building envelope, building equipment, operation and maintenance, and indoor environmental conditions. Occupants can influence the indoor thermal and air condition directly by their mere presence (emitting heat, moisture and $\mathrm{CO}_{2}$ ) or indirectly by their actions and interactions with building systems. Energy-related occupant behavior in buildings refers 
to occupants' comfort preference, presence and movement, and interactions with building systems that have an impact on performance (thermal, visual, and Indoor Air Quality (IAQ) of buildings [3].

Currently, predictions from building energy simulations cannot fully represent actual building energy use. Significant gaps between the real and predicted energy performance of buildings are caused by differences between the designed and actual construction quality, technical installations, weather conditions, model simplifications, the actual performance of the built systems, and occupant behavior [1], [4]-[6]. As buildings become more energy efficient, reducing this gap becomes more important.

Understanding and modeling occupant behavior in buildings is crucial to reducing the gap between design and actual building energy performance [7]-[9]. However, there are still very limited data to help understand occupant behavior and its impact on building performance quantitatively.

\subsection{Research gaps}

Energy-related occupant behavior research over the last decade primarily focused on the observation, understanding, and prediction of the behavioral phenomena in the office building sector [3], [10]. These observation studies focused on the relationship between behavioral actions and environmental parameters of an office space, for example indoor and outdoor temperature or day-lighting levels.

Many researchers from this field have recognized that there are many contextual factors besides environmental parameters (measurable with sensors) that may influence occupant behavior [11]-[13].

The literature shows that residential and commercial buildings of the same type, scale and with similar control options, even in similar climates, demonstrated significant variability in actual energy use. This may be caused by differences in both contextual and environmental factors influencing occupant behavior [14]. For example, Nicol conducted a survey in different countries on the window, lighting, blind, space heaters, and fan usage. He found some remarkable congruencies in lighting, heating and fan use, but significant variations as well in terms of window and blind use [15], [16].

To study and understand energy-related occupant behavior in buildings, a crosssectional questionnaire survey is a useful tool to gain insights into general behavioral patterns, drivers, causes and the perceived effect of behavior, as well as finding connections between human, social, and local comfort parameters [7], [14]. Crosssectional studies are defined as experiments in which a single measurement is made on a sample of individuals at a single point in time [17, pp. 387-402]. A limited number of large-scale cross-sectional questionnaire surveys are carried out worldwide. Their focus is more on measuring and predicting human comfort than investigating occupant behavior and motivational drivers. Consequently, the current literature lacks the general understanding of differences in occupant behavior among diverse cultures, countries, and climates [14]. 


\subsection{The status of occupant behavior implementation in Hungary}

Currently, the Hungarian construction industry regulations focusing on energy performance of buildings [18] represent occupant behavior in the static calculations with fixed heating set-points and standardized lighting power consumption. It does not include realistic, deterministic schedules (as the regulations in the USA for example [19]). As only static calculations are required, and dynamic building energy simulations are still optional and rarely used in real projects [20], [21]. This way, the relationship between contextual and environmental parameters cannot be implemented in the calculations by stochastic occupant behavior models. To improve regulations and the representation of occupant behavior in building energy performance calculations, it is essential to have ground-truth knowledge on the behavior of Hungarian building users as there might be significant cultural and contextual differences as stated above.

\subsection{Goal of this project}

The ultimate objective of this project introduced in this paper is to fill the gaps in current occupant behavior research field and as a first step, also to provide information and a complete, representative dataset on energy-related occupant behavior in offices for the Hungarian building energy sector.

\section{Methodology}

\subsection{Interdisciplinary research framework}

To investigate and quantify the human dimension in a building's energy use, an international research study has been launched as part of project ANNEX66 [2], organized by the International Energy Agency's (IEA), Energy in Buildings and Communities Programme (EBC) using an interdisciplinary framework. Despite the surge of research in recent decades, there is still a shortage of social scientists and engineers who are trained in conducting cross-country and comparative studies [2], [22].

The survey framework developed in this project is a synthesis of theories from building physics and social psychology including Social Cognitive Theory (SCT), the Theory of Planned Behavior (TPB), and the Drivers-Needs-Actions-Systems (DNAS) ontology for energy-related behaviors.

The new integrated framework has several strengths compared to each individual existing theory. These strengths condense in the selection of the most significant sociotechnical components of energy-related behaviors from each of the three frameworks, as well as the synthesis of new variables reflecting the socio-technical nature of building energy use behaviors [22].

As a research tool, an online cross-sectional survey was designed to collect crosscountry responses from office occupants among 14 universities within 6 countries (USA, China, Italy, Hungary, Poland, Australia) from 4 continents (America, Asia, Europe, Australia). This paper introduces the Hungarian data collection campaign conducted among 207 occupants in six universities across the country. Data collection 
in other countries is still an on-going effort. The survey was conducted already in three university institutions in Italy, in one university in the USA and in Hungary. The survey is currently open in several other countries (USA, three institutions in Poland, Australia, and China) Therefore, results of the international comparison are going to be published in the upcoming year.

\subsection{Cross-sectional survey}

Based on the proposed research framework, a cross-sectional survey was designed consisting of 37 questions. The survey was developed in strong collaboration between social and engineering scientists. The online survey was designed to investigate how social-psychological and demographic factors (i.e. independent variables) are related to occupants' behavioral intention in sharing the control systems (i.e. dependent variables) and identify occupants' choice of adaptive actions from a group of occupants by analyzing the statistical inference of the estimated parameters and the relative importance of each of these factors. Additionally, the survey results are expected to provide important social-psychological (e.g. group norms) findings to building efficiency solution and simulation modeling by considering both building technology and social context [22].

The survey is anonymous, and no personal identification has been/will be collected. Each survey response was/will be recorded in the Qualtrics software together with the date of compilation and geographical coordinates.

Every survey question in the questionnaire represents one or more independent variables to articulate the 37 measures of the investigation. Two additional variables (building location and season of the year) can be directly inferred from the survey without compromising data privacy issues. All measures except for control variables are estimated by participants' responses to the items with a five-point Likert-type scale [22].

To ensure future quality of international comparison results, it was crucial to apply a rigorous survey translation process. The survey instrument, originally developed in English, is translated into national questionnaires, in diverse languages (Italian, Polish, Hungarian, and Chinese). A translation guideline protocol has been developed and followed to ensure equivalence across languages. Semantic, conceptual, and normative equivalence of survey questions is guaranteed by re-translating survey questions back into English before finalizing translated versions, by following a Double Translation Process (DTP) [22], one of most adopted translation processes for survey questionnaires [22].

At the positive conclusion of the step prescribed in the translation guideline, the Italian, Polish, Hungarian, and Chinese translations have been implemented into the online Qualtrics software. Individual links to the questionnaires have been created and sent to participants in each country [22].

\subsection{The Hungarian sample}

The target group for the proposed survey was administrative staff, faculty members, and students regularly occupying their working space. The Qualtrics survey link was 
sent to the Hungarian sample through the institutional e-mailing list of six universities (Fig. 1) during the hot, summer season (from April $18^{\text {th }}$ to November $13^{\text {th }}, 2017$ ). Two reminders were sent to the participants. A total number of 207 valid responses were collected from the online questionnaire from the universities presented in Fig. 1.

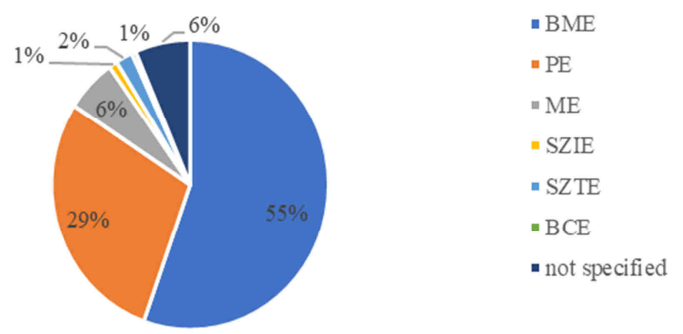

Fig. 1. Percentage of respondents from Participating universities

\section{Results of the Hungarian case}

First of all, demographic characteristics of respondents have been investigated. Gender of respondents was almost equally distributed (51\% male and 46\% female, 3\% not specified). Age distribution of the sample was proportionate as well: $18-28$ yrs. (16\%), 29-39 yrs. (33\%), 40-50 yrs. (20\%), 51-61 yrs. (19\%), >62 yrs. (12\%). A large portion of the sample population holds a $\mathrm{PhD}$ degree $(49 \%)$, or a master or an equivalent 5-year degree (26\%). According to the responses, $35 \%$ of the sample works as a professor or lecturer, $32 \%$ as administration staff, $17 \%$ researcher and $5 \%$ student, others did not specify (11\%). Cultural background of the sample is relatively homogeneous as $97 \%$ spent majority of their lives in Hungary, 3\% did not specify.

The university buildings where the respondents filled in the survey were built mainly before 1969 (1940-1969: 42\%, <1939: 19\%). Only 16\% of buildings were constructed after year 2000. Respondents most frequently occupy shared $(60 \%)$ or private offices $(28 \%)$. HVAC systems of the offices could not be surveyed in person due to the large sample size, therefore researchers had to rely on indirect survey answer information to judge the systems present (e.g. age of the building, comfort problems reported and access to cooling set-point control) and to interpret the results correctly. Shared open offices $(10 \%)$ and cubicle spaces $(0 \%)$ are not common in Hungary in a university environment. Approximately half of the respondents occupy their office for more than 31 hours per week ( $>51$ hrs. 3\%, 41-50 hrs. 13\%, 31-40 hrs. 31\%). 53\% of the sample spends less than 30 hours per week at their desks.

Participants indicated that they have access to the environmental control options as it is shown in Fig. 2. Based on the answers, it can be seen that $92 \%$ has access to open and close windows, and respondents are aware of this control option as well. This is followed by the shading control option by $74 \%$ having access to it. Only $56 \%$ of respondents stated that they have access to temperature controls and somewhat only $62 \%$ indicated the option to use lighting controls. The question asked about their ability to use these controls, therefore the mere existence of a control option does not mean 
accessibility in case of this question group. 6 participants stated that they are not aware whether they have access to temperature or shading controls. This is strongly connected to the measured knowledge on controls investigated below.

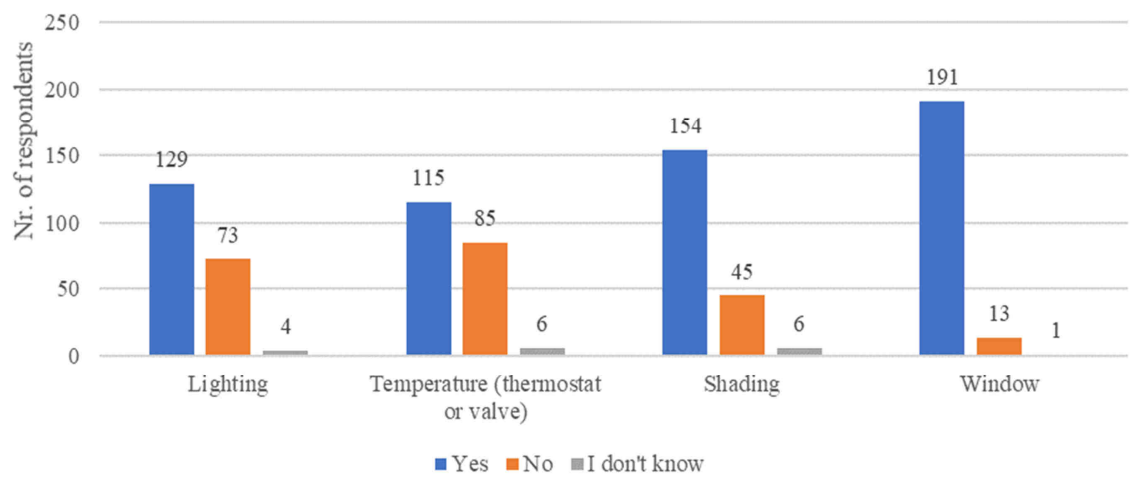

Fig. 2. Access to environmental control options

$18 \%$ stated that they share environmental control options with one other colleague and $49 \%$ with 2 or more co-workers. This is in correspondence with the answers to the question on office types where $70 \%$ stated that they occupy either shared or open offices as work.

Respondents' current comfort levels and satisfaction (Fig. 3): 54\% of respondents felt warm or hot at the time of replying to the survey questions (average thermal comfort votes on the Predicted Mean Vote (PMV) scale (-3 to +3$)$ : 0.79). Current satisfaction vote of respondents can be seen with five different indoor environmental parameters on a Likert scale in Fig. 3. Majority of the sample is satisfied with both natural $(64 \%)$ lighting levels in their offices and almost half of the sample (46\%) stated satisfaction with artificial lighting. $38 \%$ of respondents stated that they feel neutral in connection with acoustic parameters of their offices. $42 \%$ of the sample stated that they are satisfied with the indoor air quality. The most unsatisfied answers arrived in the category of indoor air temperature: $39 \%$.

Causes of discomfort in general were asked from respondents. In this case, there was a chance to thick in multiple answers. It was found that thermal discomfort is caused by air drafts (from windows and/or air conditioning systems, 72 votes out of 207) and thermostat is not accessible or controlled by others ( 47 votes). Cold ( 25 votes) or hot ( 28 votes) surfaces (walls and floors) and the vicinity of windows ( 25 votes) were stated as thermal discomfort causes as well. Visual discomfort is caused mainly by glare on the computer screens ( 72 votes) and too much artificial light (35 votes). 62 respondents replied that there is not enough natural daylight in their workspace. Most crucial causes of acoustic discomfort were poor acoustic insulation of facades (outside noise can be heard inside, 88 votes) and poor indoor noise insulation between spaces (disturbing indoor chatting from neighboring rooms, 88 votes). Equipment and other mechanical system background noises cause acoustic discomfort in case of 55 respondents. 
According to respondents, poor indoor air quality in their office spaces is caused by bad, strong odors and scents (63 votes) and by poor mechanical ventilation systems (54 votes).

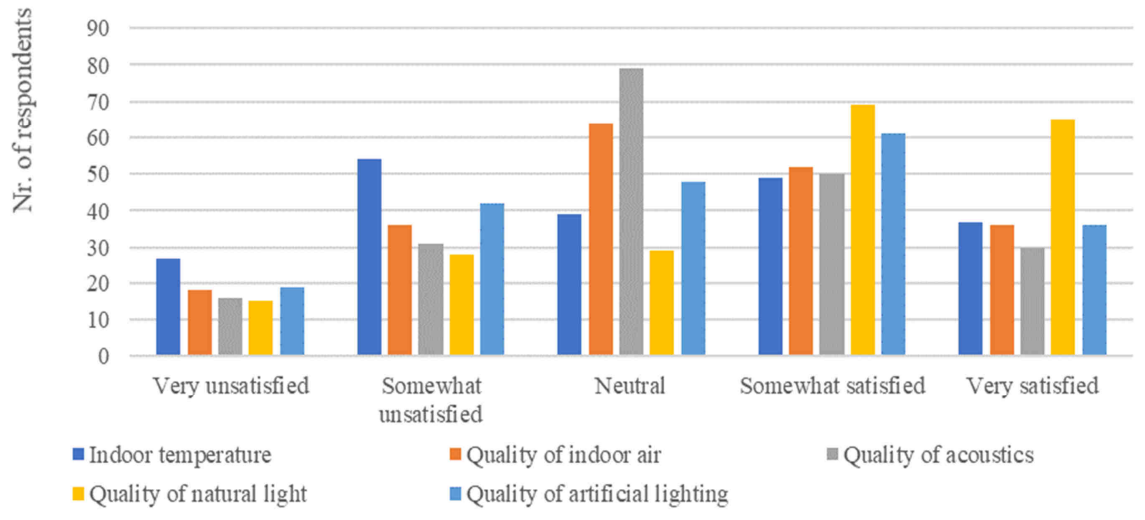

Fig. 3. Current Satisfaction of the sample with environmental parameters

Motivation and drivers to use controls have been asked in 6 questions in each season and control options. Here again, more than one answers were allowed. Respondents stated (Fig. 4) that their window opening behavior is driven by the need for fresh air in all seasons. The regulation of indoor temperature levels is a dominant secondary driver $(56 \%)$ during the summer season whereas in other seasons it shows less importance (36\%, 28\%, 28\% in spring, autumn and winter seasons). Approximately one third (35\%, $38 \%, 33 \%$ and $26 \%$ in spring, summer, autumn and winter seasons respectively) of the respondents indicated that their window opening behavior is strongly connected to their arrival to the office especially during summer and transitional seasons.

Window-closing drivers show a more differentiated picture in each season. During winter and summer, the primary driver is the outdoor temperature followed by indoor temperature in winter and the decrease of outdoor noises in summer. In transitional seasons the primary driver is to reduce outdoor noises followed by arriving/leaving the space. Primary motivation for closing the blinds in the office space was arriving/leaving the office except for summer when the most important goal was to reduce overheating due to direct sunlight. Only $8 \%$ indicated that they close blinds because of glare on their workstations. The opening of the blinds was driven by letting more daylight into the space primarily followed by the motivation to have a direct view to the outside in all seasons. Respondents answered that they adjust heating or cooling in the office primarily because the indoor temperature is too hot or cold. Only $11 \%, 8 \%, 11 \%$ and $13 \%$ responded that they wanted to save energy by adjusting the thermostat or the valve in spring, summer, autumn and winter conditions respectively. Occupants switched on the light primarily to have more light at their workplace followed by arriving at the office. Whereas switching off the light was driven by leaving the office and followed by energy conservation and having too much light at the workplace. 


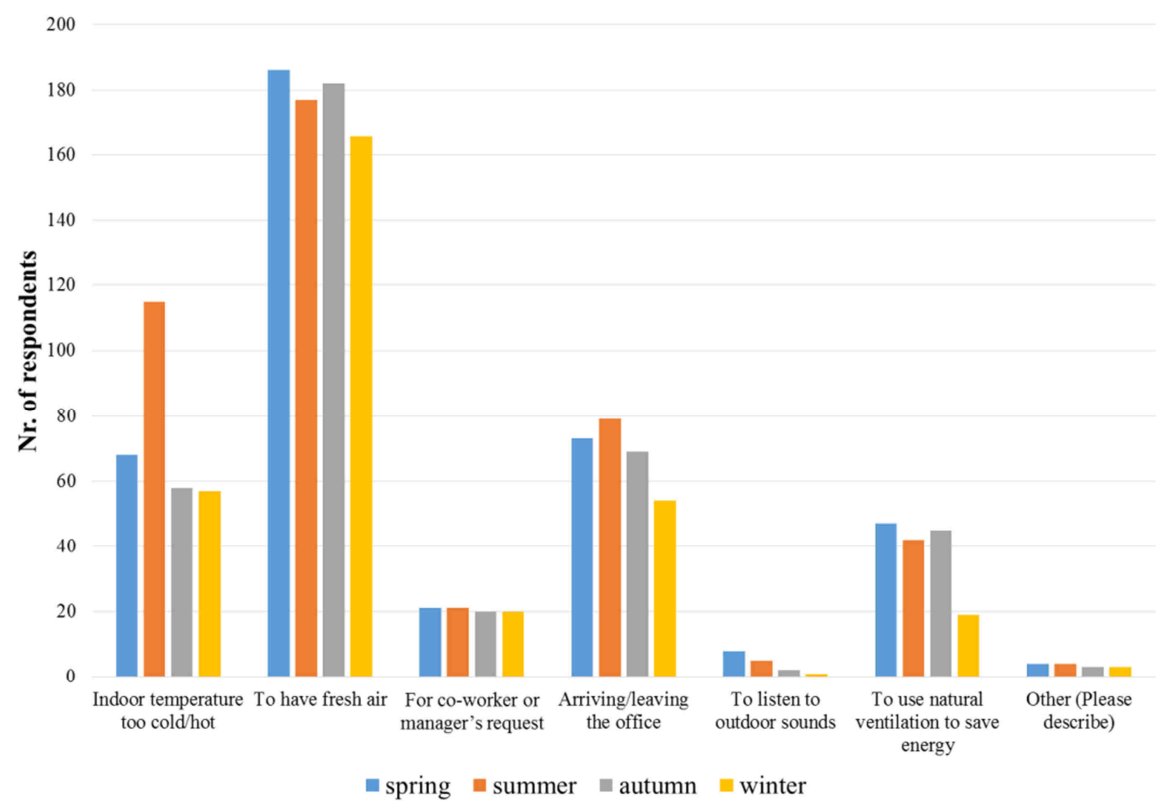

Fig. 4. Drivers to open a window during different seasons

In terms of group behavior in the office environment, $53 \%$ stated that they operate the controls by meeting the needs of those who express discomfort, $23 \%$ experienced group discussion on control use in the office environment. Negotiations over control use take place most often on window (69\% of the sample experienced) and lighting $(65 \%)$ use. In case of windows, the negotiation frequency is more than once a day whereas in case of lighting control it is less than once a week.

Respondents' votes on the knowledge of different control usage showed that the sample was most confident in using the light switches (4.72 average vote on the scale from 1 to 5 where 5 indicates the full agreement with the statements on knowledge) and window opening/closing (4.71). Whereas thermostat or heating control valve was used less confidently (4.18). Occupants preferred to open the window first when they were feeling hot during summer season and then secondly, they prefer to have a cold drink. This is followed by shading closing and clothing level adjustments. Whereas in case they feel cold during summer season, respondents indicated that they first increase clothing levels, then close the windows and these are followed by having a hot drink.

\section{Discussion}

The Hungarian sample can be considered as a statistically representative proportion of the population under investigation. As university staff was in Hungary 22,400 persons in 2016 [23], the minimum sample size is 195 respondents with $\pm 7 \%$ sampling error and with $95 \%$ confidence level using the Dillman formula [24]. Both genders are 
proportionately represented. Large proportion of the sample (49\%) holds a PhD degree, which has to be considered during possible national level generalization of the findings of this study. $97 \%$ of the sample stated that they grew up in Hungary. Therefore, it can be assumed that the sample is culturally homogeneous.

Majority of the respondents spends more than 31 hours at their workplace, this way their behavior can be assumed to be applicable for majority of the working week.

$54 \%$ of respondents felt warm or hot at the time of replying to the survey questions. This shows that summer comfort levels are low in the university buildings (average thermal comfort vote on the PMV scale $(-3$ to +3$): 0.79)$. This may be caused by that half of university buildings are not equipped with air-conditioning (56\% had access to cooling in the sample) and majority of the sample buildings were built before 1969 without retrofitting works carried out.

In case of window opening, after the fresh air supply, the regulation of indoor temperature levels is a dominant secondary driver $(56 \%)$ during the summer season whereas in other seasons it shows less importance $(36 \%, 28 \%, 28 \%$ in spring, autumn and winter seasons). These drivers of window use are frequently measured in smallscale experimental studies investigating window opening behavior in office settings [25], [26], [27].

Respondents' votes on the knowledge of different control usage showed that the sample was most confident in using the light switches (4.72 average vote on the scale from 1 to 5 where 5 indicates the full agreement with the statements on knowledge) and window opening/closing (4.71). Whereas thermostat or heating control valve was used less confidently (4.18). This shows the lack of education programs on more complicated environmental controls.

As $70 \%$ of the sample worked in a shared or open office environment, group behavior trends could be shown in environmental control use, which adds new knowledge to the field. Negotiations over control use take place most often on window (69\% of the sample experienced) and lighting (65\%) use. In case of windows, the negotiation frequency is more than once a day whereas in case of lighting control it is less than once a week.

Occupants preferred to open the window first when they were feeling hot during summer season and then secondly, they prefer to have a cold drink. This is followed by shading closing and clothing level adjustments. Whereas in case they feel cold during summer season, respondents indicated that they first increase clothing levels, then close the windows and these are followed by having a hot drink. This is a new area of research in this field, which gives an opportunity to determine the share of active (e.g. window, shading use) and passive (e.g. drinks, clothing level adjustments) environmental control usage in office environments.

\section{Future work}

This work is part of an ongoing international effort. Therefore, future steps include the successful conclusion of the data collection campaigns in all countries. This is followed by data cleaning and data agreement processes to be able to compare the 
international datasets. Authors hope that the results of the comparison will provide valuable, new knowledge to the field of energy-related occupant behavior in building.

Results of the Hungarian data collection campaign could be used locally to inform building energy policy makers by use-patterns and so-called behavioral schedules to be implemented into building energy simulation practice and guidelines.

\section{Conclusion}

This paper introduces the first statistically representative dataset on energy-related office occupant behavior in Hungary. Based on this dataset, motivating factors and use patterns were determined for window, shading, lighting and temperature controls.

In many cases, behavioral patterns, motivational factors and group behavior trends show good agreement with relevant international literature. At some time, new knowledge could be added to the field in terms of order of comfort-restoring actions. Based on the responses on knowledge of controls, the lack of education programs on more complicated environmental controls was shown. This way large-scale control use training programs can be advised country-wide.

Based on the results of this study, ground truth knowledge can be filtered to support the improvement of the Hungarian energy performance regulations and guidelines for building energy simulation.

\section{Acknowledgements}

Authors would like to express their gratitude to the ANNEX66 survey framework developer team consisting of Chien-fei Chen, Tianzhen Hong, Simona D'Oca and Zsófia Deme Bélafi. Special thanks should go also to the team at Center for Ultra-Wide-Area Resilient Electrical Energy Transmission Networks (CURENT), University of Tennessee, Knoxville, USA for their continuous support during the online data collection process, namely, Jacqueline

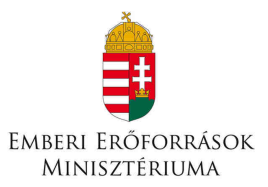
Adams and Chien-fei Chen. This work was supported by the ÚNKP-17-3-I New National Excellence Program of the Ministry of Human Capacities, Hungary.

\section{References}

[1] Polinder H., Schweiker M., Van Der A., Schakib-Ekbatan K., Fabi V., Andersen R., Morishita N., Wang C., Corgnati S., Heiselberg P., Yan D., Olesen B., Bednar T., Wagner A. Occupant behavior and modeling, Final Report Annex 53, International Energy Agency Programme on Energy in Buildings and Communities, AECOM Ltd., Hertfordshire, 2016.

[2] Yan D., Hong T. Definition and simulation of occupant behavior in buildings, IEA EBC Annex 66, International Energy Agency Programme on Energy in Buildings and Communities 2014, http://annex66.org/, (last visited 12 December 2017). 
[3] Hong T., Taylor-Lange S. C., D’Oca S., Yan D., Corgnati S. P. Advances in research and applications of energy-related occupant behavior in buildings, Energy and Build., Vol. 116, 2015, pp. 694-702.

[4] Norford L. K., Socolow R. H., Hsieh E. S., Spadaro G. V. Two-to-one discrepancy between measured and predicted performance of a 'low-energy' office building: insights from a reconciliation based on the DOE-2 model, Energy and Build., Vol. 21, No. 2, 1994, pp. 121-131.

[5] Hoes P., Hensen J. L. M., Loomans M. G. L. C., de Vries B., Bourgeois D. User behavior in whole building simulation, Energy and Build., Vol. 41, No. 3,2009, pp. 295-302.

[6] Bourgeois D. Detailed occupancy prediction, occupancy-sensing control and advanced behavioural modelling within whole-building energy simulation, PhD Thesis, Fac. des études supérieures, Univ. Laval, Québec, 2005.

[7] Yan D., O'Brien W., Hong T., Feng X., Gunay B., Tahmasebi, F., Mahdavi, A.Occupant behavior modeling for building performance simulation: Current state and future challenges, Energy Build., Vol. 107,2015, pp. 264-278.

[8] Turner C., Frankel M. Energy performance of LEED ${ }^{\circledR}$ for new construction buildings, New Build. Inst, pp. 1-46, 2008.

[9] Gunay H. B., O'Brien W., Beausoleil-Morrison I. A critical review of observation studies, modeling, and simulation of adaptive occupant behaviors in offices, Building and Environment, Vol. 70, 2013, pp. 31-47.

[10] Hong T., Yan D., D'Oca S., Chen C. Ten questions concerning occupant behavior in buildings: The big picture, Building and Environment, Vol. 114, 2016, pp. 518-530.

[11] O'Brien W., Gunay H. B. The contextual factors contributing to occupants' adaptive comfort behaviors in offices - A review and proposed modeling framework, Build. Environ., Vol. 77, 2014, pp. 77-87.

[12] Langevin J., Gurian P., Wen J. Tracking the human-building interaction: Findings from a longitudinal field study of occupant behavior in air-conditioned offices, J. Environ. Psychol, Vol. 42, 2015, pp. 94-115.

[13] De Dear R., Brager G. S. Developing an adaptive model of thermal comfort and preference, ASHRAE Trans, Vol. 104, Part 1, 1998, pp. 1-18.

[14] Belafi Z., Hong T., Reith A. A critical review on questionnaire surveys in the field of energy-related occupant behavior, Energy Efficiency (under publ.) 2017.

[15] Nicol J. F. Characterising occupant behavior in buildings: Towards a stochastic model of occupant use of windows, lights, blinds heaters and fans, Seventh Int. IBPSA Conf, Rio de Janeiro, Brazil, 13-15 August 2001, pp. 1073-1078.

[16] Nicol J. F., Humphreys M. A. A stochastic approach to thermal comfort - Occupant behavior and energy use in buildings, ASHRAE Trans, Vol. 110, No. 2, 2004, pp. 554-568.

[17] de Leeuw E. D., Hox J. J., Dillman D. A. International handbook of survey methodology, Routledge, Abingdon, 2008.

[18] Hungarian transposition of EPBD: TNM Ministry Decree No. 7/2006 (V. 24), Government Decree 176/2008 (VI. 30), Governmental Decree 264/2008. (XI. 6) (in Hungarian).

[19] Energy estimating and modeling methods, In ASHRAE handbook - Fundamentals, 2009.

[20] Póth B., Kistelegdi I. Energy and climate simulations and management system in the Szentágothai research center, Pollack Periodica, Vol. 9, No. 1, 2014, pp. 61-70.

[21] Kővári G., Kistelegdi I. Building performance simulation modeling, Pollack Periodica, Vol. 11, No. 2, 2016, pp. 135-146.

[22] D’Oca S., Chen C., Hong T., Belafi Z. Synthesizing building physics with social psychology: An interdisciplinary framework for context and behavior in office buildings, Energy Ressearch and Social Sciences, Vol. 34, 2017, pp. 240-251.

[23] Statisztikai tükör 2017, (in Hungarian) Központi Statisztikai Hivatal, 2017, pp. 1-9.

[24] Dillman D. A. Mail and internet surveys: the tailored design method, Wiley, 2007. 
[25] Fabi V., Andersen R. V., Corgnati S., Olesen B. W., Occupants' window opening behavior, A literature review of factors influencing, Build. Environ, Vol. 58, 2012, pp. 188-198.

[26] Haldi F., Robinson D. Interactions with window openings by office occupants, Build. Environ, Vol. 44, 2009, pp. 2378-2395.

[27] Stazi F., Naspi F., D'Orazio M. A literature review on driving factors and contextual events influencing occupants' behaviors in buildings, Build. Environ, Vol. 118, 2017, pp. 40-66. 